\title{
The Alpha-2A Adrenergic Receptor Gene -1291C/G Single Nucleotide Polymorphism is Associated with the Efficacy of Methylphenidate in Treating Taiwanese Children and Adolescents with Attention-Deficit Hyperactivity Disorder
}

\author{
Hui-Ching Huang ${ }^{1,2}$, Lawrence Shih-Hsin $\mathrm{Wu}^{3}$, Shun-Chieh $\mathrm{Yu}^{4}$, \\ Bo-Jian $\mathrm{Wu}^{4}$, Ahai Chang Lua ${ }^{5}$, Shin-Min Lee ${ }^{6,7}$, and Chao-Zong Liu' ${ }^{凶}$ \\ ${ }^{1}$ Department of Pharmacy, Yuli Hospital, Ministry of Health and Welfare, Hualien, Taiwan \\ ${ }^{2}$ Department of Pharmacology, School of Medicine, Tzu Chi University, Hualien, Taiwan \\ ${ }^{3}$ Institute of Medical Science, Tzu Chi University, Hualien, Taiwan \\ ${ }^{4}$ Department of General Psychiatry, Yuli Hospital, Ministry of Health and Welfare, Hualien, Taiwan \\ ${ }^{5}$ Department of Laboratory Medicine and Biotechnology, Tzu Chi University, Hualien, Taiwan \\ ${ }^{6}$ Department of Psychiatry, Tri-Service General Hospital, National Defense Medical Center, Taipei, Taiwan \\ ${ }^{7}$ Department of General Psychiatry, Taoyuan Psychiatric Center, Ministry of Health and Welfare, Taoyuan, Taiwan
}

Objective The therapeutic effect of methylphenidate (MPH) in treating attention-deficit/hyperactivity disorder (ADHD) has been related to the alpha-2A adrenergic receptor (ADRA2A) gene -1291C/G single nucleotide polymorphism (SNP). We investigated the effect of MPH in treating Taiwanese children and adolescent with ADHD and its relation to the ADRA2A gene -1291C/G SNP.

Methods The subjects with DSM-IV ADHD diagnosis underwent a titration period to find out the dose of MPH for maintenance treatment. After 4 weeks maintenance treatment, the effect of MPH was evaluated by the Swanson, Nolan and Pelham version IV total scores. The subjects with more than $25 \%$ score reduction were referred to responders and those with $\geq 50 \%$ improvement were considered as better responders. The $-1291 \mathrm{C} / \mathrm{G}$ variant of the ADRA2A gene was identified by DNA sequencing and what relevance it has to the MPH response was examined by binary logistic regression analysis.

Results Of the 59 subjects, 44 (74.6\%) were responsive to MPH treatment and the responsiveness was not shown to be associated with the ADRA2A gene -1291C/G SNP. As the responsive subjects were categorized as moderate responders and better responders and subjected to statistical analysis, the GG homozygotes showed a greater chance to have a better response to MPH treatment than CC homozygotes $(\mathrm{p}=0.02)$, with an odds ratio of $32.14(95 \% \mathrm{CI}=1.64-627.80)$.

Conclusion The ADRA2A gene -1291C/G SNP is associated with the efficacy of MPH for the treatment of ADHD in Taiwanese children and adolescents. The responsive subjects bearing homozygous $-1291 \mathrm{G}$ allele are more likely to have a better response to MPH treatment.

Psychiatry Investig 2018;15(3):306-312

Key Words Attention-deficit/hyperactivity disorder, Alpha-2A adrenergic receptor, Methylphenidate, Pharmacogenetics.

\section{INTRODUCTION}

Attention-deficit hyperactivity disorder (ADHD) is one of

Received: November 4, 2016 Revised: June 15, 2017

Accepted: July 24, 2017

$\triangle$ Correspondence: Chao-Zong Liu, $\mathrm{PhD}$

Department of Pharmacology, School of Medicine, Tzu Chi University, No. 701, Zhongyang Road, Sec. 3, Hualien City 97004, Taiwan

Tel: +886 03-8565301 ext 2068, Fax: +886-3-856-1465

E-mail: czliu33@mail.tcu.edu.tw

(a) This is an Open Access article distributed under the terms of the Creative Commons Attribution Non-Commercial License (http://creativecommons.org/licenses/bync/4.0) which permits unrestricted non-commercial use, distribution, and reproduction in any medium, provided the original work is properly cited. the most common mental disorders occurred in children noted for the symptoms of inattention, hyperactivity, and impulsivity. ${ }^{1,2}$ It is hypothesized that all the symptoms of ADHD arise from the abnormalities in various circuits involving prefrontal cortex (PFC), ${ }^{3}$ and optimal levels of dopamine (DA) and norepinephrine (NE) acting at the postsynaptic dopaminergic receptor and alpha-2A adrenergic receptor (ADRA2A) are required for the PFC to function properly, ${ }^{4-6}$ either too much or too little stimulation by DA or NE can cause inefficient information processing. ${ }^{7-9}$

Stimulant medications are considered the most effective 
treatment for ADHD under the age of 18, and the first-line choice of psychostimulants is methylphenidate (MPH).,10-12 MPH blocks the reuptake pumps for both DA and NE, thereby increasing the levels of DA and NE in the synapse. ${ }^{13,14}$ It has been shown that MPH at the doses that improve cognitive function increases the levels of DA and NE in the PFC. ${ }^{15}$

Pharmacogenetics is a research field encompassing the analysis of gene variants that are associated with the variability of drug response and adverse drug reaction. This field has grown rapidly and some of the results have been implemented in clinical practice for personalized drug treatment. ${ }^{16-18} \mathrm{MPH}$ treatment is considered effective and safe for ADHD patients, with a response rate of $65-80 \%,{ }^{2,19,20}$ but there was considerable inter-individual variability among patients regarding response to treatment, required doses, and adverse events. ${ }^{11}$ The etiology of ADHD remains unclear but it was considered that genetic factors are involved. ${ }^{21}$ Some studies focused on the genes that influence the clinical response to $\mathrm{MPH}$ treatment, ${ }^{22}$ and the ADRA2A gene -1291C/G SNP (rs1800544) recently became a genetic polymorphism of interest. It was reported that the symptoms of ADHD was associated with the ADRA2A gene $-1291 \mathrm{C} / \mathrm{G} \mathrm{SNP}, 23,24$ and the carriers of homozygous - $1291 \mathrm{G}$ allele displayed better response to MPH treatment. ${ }^{25-27}$ Some studies on the other hand failed to relate the MPH response to the ADRA2A gene -1291C/G SNP. ${ }^{28,29}$

In Taiwan, MPH is the most prescribed psychostimulant for the treatment of ADHD under the age of 18. It remains unclear whether the MPH response is associated with the ADRA2A gene $-1291 \mathrm{C} / \mathrm{G}$ SNP. This study aims to investigate the effect of MPH in treating Taiwanese children and adolescents with ADHD and its relation to the ADRA2A gene -1291C/G SNP, hoping to find out a genetic marker that is associated with the $\mathrm{MPH}$ response. Liver carboxylesterase 1 (CES1) is one of the major enzymes responsible for the metabolism of MPH. ${ }^{30,31}$ A CES1 gene variant (rs71647871) associated with reduced enzyme activity was recently identified and shown to be linked with the dosage of MPH. ${ }^{32,33}$ This genetic variant was also anlayzed in this study.

\section{METHODS}

\section{Subjects}

This study enrolled 59 ADHD children (mean age $=11.47 \pm$ 1.77 years, 53 boys and 6 girls) from a child psychiatric clinic in Hualien City, Hualien County, Taiwan. The diagnosis was made by an interview with children and their family according to the Diagnostic and Statistical Manual of Mental Disorders 4th ed. (DSM-IV-TR), and behavior observation. More than three appointments were required for ADHD diagnosis. Children underwent physical, neurological, and developmen- tal examinations during each visit. Parents were asked to provide background records and school reports as well as to complete behavior rating scales of Swanson, Nolan and Pelham version IV (SNAP-IV) before and after MPH treatment.

For this study, the inclusion criteria were: 1) diagnosis of ADHD according to the DSM-IV Diagnostic Criteria of Mental Disorders, 2) age 6-18 years, 3) agreement to participate in the study with informed consent, and 4) without taking any medicine for ADHD treatment at the first appointment. The exclusion criteria were: 1) a past or present history of brain damage or convulsive disorder, 2) mental retardation, autism, language difficulties, or developmental problems including learning disability. None of the children received co-medication that can influence the metabolism and the effect of MPH. This study was approved by the Ethic Review Committee of Yuli Hospital (Approval number: YLH-IRB-9916). Informed consent was obtained from all subjects and their parents prior to commencement.

\section{The MPH regimen}

The subjects with ADHD diagnosis first underwent a dose titration to find out the optimal dose of MPH for maintenance treatment. During dose titration period, MPH was administered with an increasing dosage regimen until no further clinical improvement was detected or until limited adverse effects occurred. Dosage adjustment proceeded weekly and once the maintenance dose was determined, MPH was administered at this dosage for an additional 4 weeks. If improvement is not observed after appropriate dosage adjustment over a one-month period, the MPH treatment should be discontinued. The maintenance dose of MPH varied among individuals, ranging from 10 to $72 \mathrm{mg} /$ day. The mean daily dose of MPH adjusted by body weight appears to be $0.90 \pm 0.30 \mathrm{mg} / \mathrm{kg} /$ day (range: 0.21-1.58). Dosage form of MPH was also variable. Subjects were treated with extended-release tablet $\left(\right.$ Concerta $^{\circledR}, 18,27$, 36, and $54 \mathrm{mg}$; Johnson \& Johnson Taiwan Ltd., Taipei, Taiwan) $(n=57)$, immediate-release tablet $\left[\operatorname{Ritalin}^{\circledR}, 10 \mathrm{mg}\right.$; Novartis (Taiwan) Co., Ltd., Taipei, Taiwan] $(n=1)$, or a combination of both $(n=1)$.

\section{Evaluation of the therapeutic effect of MPH}

The therapeutic effect of MPH was evaluated by the Chinese version of the SNAP-IV Parent Form, a widely used behavior rating scales for the measure of ADHD in Taiwan. The Chinese version SNAP-IV scale-parent and teacher forms were translated by Gau et al., and its validity and reliability on ADHD had been validated. ${ }^{34-36}$ It is a 26 -item scale using a 4-point Likert scale with a score of 0 for "not at all," 1 for "just a little," 2 for "quite a bit," and 3 for "very much." It contains 18 items parallel to the core symptoms in the DSM-IV-TR 
for ADHD (Items 1-9 for inattention symptoms; Items 1018 for hyperactivity/impulsivity symptoms) and eight symptom items for oppositional defiant disorder (ODD) according to the DSM-IV-TR criteria. The subjects with more than $25 \%$ reduction in the SNAP-IV total scores were considered responsive to MPH treatment, according to previous studies. ${ }^{19,37}$

\section{Genotyping}

The SNPs of ADRA2A gene (-1291C/G) and CES1 gene (428G/A) were identified by sequencing the corresponding DNA segments reproduced by PCR. The DNA segment (92bp) encompassing the $-1291 \mathrm{C} / \mathrm{G}$ SNP of ADRA2A gene was copied from the genomic DNA with the primer pair 5'-ACGTTGGATGTTCTCCCAAGATCCAGCTTC (sense) and 5'ACGTTGGATGCCTGCTG GGAGTTGGCCAT (antisense).$^{25}$ PCR was carried out in a Biometra ${ }^{\circledR}$ thermocycler (Model: T-1 Thermoblock, Biometra, Gottingen, Germany) with 37 cycles of denaturation $\left(98^{\circ} \mathrm{C}\right.$ for $\left.10 \mathrm{~s}\right)$, primers annealing $\left(68^{\circ} \mathrm{C}\right.$ for $\left.30 \mathrm{~s}\right)$ and extension $\left(72^{\circ} \mathrm{C}\right.$ for $\left.45 \mathrm{~s}\right)$. The DNA segment (615-bp) franking the 428G/A SNP of CES1 gene was reproduced with the primers 5'-TGATGGGAGTGTCCTCCCGAAG (sense) and 5'-GGGTAGGTAGTGTGTCCAATTAC (antisense). ${ }^{33}$ Reaction consisted of 37 cycles of denaturation $\left(98^{\circ} \mathrm{C}\right.$ for $\left.10 \mathrm{~s}\right)$, primers annealing $\left(60^{\circ} \mathrm{C}\right.$ for $30 \mathrm{~s}$ ) and extension $\left(72^{\circ} \mathrm{C}\right.$ for $\left.45 \mathrm{~s}\right)$. The PCR products verified by agarose gel electrophoretic analysis were purified and then subjected to DNA sequencing. DNA sequencing was performed with an automatic sequencer (ABI 3730 DNA analyzer, Applied Biosystems, Waltham, MA, USA). Genomic DNA was isolated from peripheral leucocytes using the QIAamp ${ }^{\circledR}$ DNA Blood Mini Kit (QIAGEN, Valencia, CA, USA).

\section{Statistical analysis}

Binary logistic regression analysis including the common clinical demographics (gender, age, BMI, MPH daily dose) was employed to examine the impact of the ADRA2A gene -1291C/G SNP (CC homozygous, CG heterozygous, GG homozygous) on the MPH response. The SPSS program version 11.5 (SPSS Inc., Chicago, IL, USA) was used for statistical analysis. The significance level was set at a value of 0.05 (two-tailed).

\section{RESULTS}

Our subjects consist of 5 CC homozygotes, 20 GG homozygotes and $34 \mathrm{CG}$ heterozygotes according to genotyping. The allele frequencies for the included subjects were 0.37 and 0.63 for the $\mathrm{C}$ and $\mathrm{G}$ allele, respectively, and the genotype frequencies were under Hardy-Weinberg equilibrium. The examples of DNA sequencing signals around the ADRA2A gene -1291 C/G SNP were shown in the Supplementary Figure 1 (in the online-only Data Supplement). The CES1 gene 428G/ A SNP (rs71647871) that found in Caucasian was not revealed in our subjects $(n=59)$. All the subjects bear homozygous $428 \mathrm{G}$ allele in the CES1 gene (data not shown).

Before MPH treatment, the average SNAP-IV score of our subjects ( $n=59)$ was $46.53 \pm 13.61$. After treatment with maintenance dose of MPH for 4 weeks, 44 subjects exhibited more than $25 \%$ score reduction. These results indicate that $74.6 \%$ (44/59) of our subjects are responsive to MPH treatment. The response rates for the $\mathrm{CC}$ homozygotes, $\mathrm{CG}$ heterozygotes and GG homozygotes were 100\% (5/5), 79.4\% (27/34) and 60\% (12/20), respectively. Table 1 shows the common clinical demographic data (gender, age, BMI, and MPH daily dose) for the MPH responders and non-responders. No significant dif-

Table 2. The effects of genetic polymorphism (-1291C/G) and clinical demographics on the MPH response

\begin{tabular}{lccc}
\hline \multicolumn{1}{c}{ Independent variables } & OR & $95 \%$ CI & p-value \\
\hline Gender & 0.80 & $0.84-7.78$ & 0.85 \\
Age & 0.92 & $0.62-1.37$ & 0.69 \\
BMI & 1.33 & $0.99-1.78$ & 0.05 \\
Daily dose (mg/day) & 1.01 & $0.93-1.10$ & 0.68 \\
Genotype & & & \\
$\quad$ C/G vs. C/C & 0.0001 & $0.0001-\mathrm{NA}$ & 0.99 \\
$\quad$ G/G vs. C/C & 0.0001 & $0.0001-\mathrm{NA}$ & 0.99 \\
\hline
\end{tabular}

The subjects received MPH treatment were categorized as non-responders and responders and subjected to binary logistic regression analysis. Those with more than $25 \%$ reduction in the SNAPIV total scores were referred as responders. OR: odds ratio, CI: confidence interval, MPH: methylphenidate, BMI: body mass index, NA: not available, SNAP-IV: Swanson, Nolan and Pelham version IV

Table 1. The clinical demographics of MPH responders and non-responders

\begin{tabular}{lccc}
\hline \multicolumn{1}{c}{ Variables } & Non-responder & Responder & p-value \\
\hline Gender, female/male $(\mathrm{N})^{\mathrm{a}}$ & $2 / 13$ & $4 / 40$ & 0.63 \\
Age, years $(\text { mean } \pm \mathrm{SD})^{\mathrm{b}}$ & $11.66 \pm 1.87$ & $11.40 \pm 1.75$ & 0.63 \\
BMI (mean $\pm \mathrm{SD})^{\mathrm{b}}$ & $16.59 \pm 1.88$ & $18.92 \pm 3.77$ & $<0.01$ \\
Daily dose $\left(\mathrm{mg} /\right.$ day) $(\text { mean } \pm \mathrm{SD})^{\mathrm{b}}$ & $34.60 \pm 6.34$ & $35.61 \pm 11.44$ & 0.74 \\
\hline
\end{tabular}

The differences in the gender distribution, age, BMI and MPH daily dose between MPH responders (with more than 25\% score reduction) and non-responders were examined by independent t-test (b) or chi-square test (a). MPH: methylphenidate, BMI: body mass index, SD: standard deviation 
ferences in the clinical demographics were found between responders and non-responders, except BMI. Binary logistic regression analysis including the clinical demographics failed to demonstrate an impact of genetic polymorphism (-1291C/ $\mathrm{G}$ ) on the MPH response (Table 2). We next studied the extent of improvement in the 44 responders and its relation to the ADRA2A gene -1291 C/G SNP. There was no significant difference in the SNAP-IV total scores among CC homozygotes, CG heterozygotes, and GG homozygotes before MPH treatment (Figure 1). After MPH treatment, the subjects with the $-1291 \mathrm{G}$ allele exhibited more score reduction, notably in the GG homozygotes (Figure 1). These results indicate that the responsive subjects bearing the $-1291 \mathrm{G}$ allele tend to have more score reduction following MPH treatment. But, there was no significant difference among genotypes as analyzed by oneway ANOVA analysis $(\mathrm{p}=0.31)$. As the responsive subjects $(\mathrm{n}=$ 44) were further categorized as moderate responders and better responders by $\geq 50 \%$ improvement, $20 \%$ of CC homozygotes (1/5), 55.6\% of CG heterozygotes (15/27), and $83.3 \%$ of GG homozygotes (10/12) could be referred to the group of better responders ( $\geq 50 \%$ improvement). Analyzed by binary logistic regression model including the demographics (gender, age, $\mathrm{BMI}$, daily dose of $\mathrm{MPH}$ ), the responsive subjects homozygous

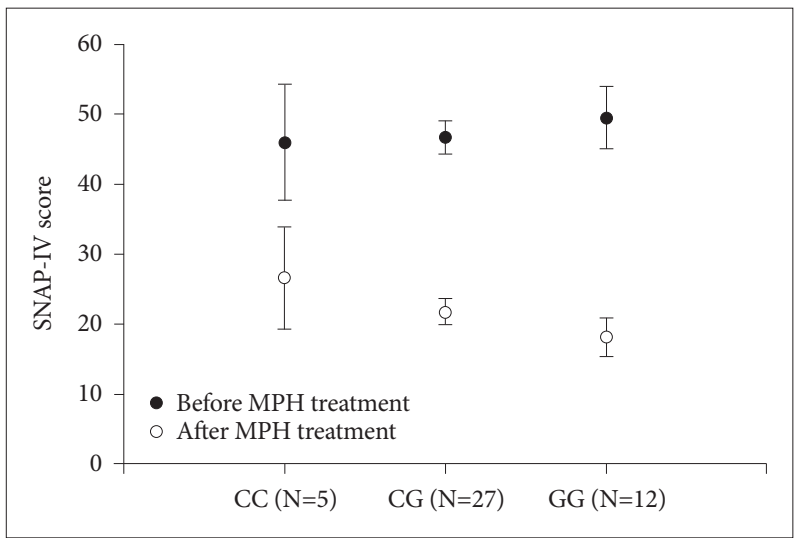

Figure 1. The change of SNAP-IV total scores in the responding subjects with different genotypes following MPH treatment. Close circles and open circles represent the SNAP-IV scores before and after MPH treatment, respectively, in the subjects with different genotypes (CC, CG, GG). Data were shown as mean \pm SEM. MPH: methylphenidate, SEM: standard error mean, SNAP-IV: Swanson, Nolan and Pelham version IV. for the $-1291 \mathrm{G}$ allele showed a greater chance to have a better response to $\mathrm{MPH}$ treatment than CC homozygotes ( $\mathrm{p}=0.02)$, with an odds ratio of 32.14 (95\% CI=1.64-627.80). The CG heterozygotes also presented a greater chance to have a better response to MPH treatment in comparison with CC homozygotes. The odds ratio appeared to be 5.98 , but the tendency failed to reach statistical significance $(\mathrm{p}=0.18)$. The demographics data for the moderate responders and better responders were shown in Table 3. The results of binary logistic regression analysis were shown in Table 4.

\section{DISCUSSION}

The ADRA2A receptors expressed on the dendritic spines of prefrontal cortical pyramidal neurons are important modulators of the PFC function ${ }^{7}$ and related to the therapeutic effect of MPH. ${ }^{9}$ The gene encodes the ADRA2A receptor is located on chromosome 10q24-26, in which the -1291 C/G SNP (rs1800544) identified by Lario et al..$^{38}$ was recently shown to be associated with the therapeutic effect of MPH in treating children and adolescents with ADHD, the homozygous -1291G allele was linked to a better response to MPH treatment. ${ }^{27}$ The association of the ADRA2A gene -1291C/G SNP with the MPH response in Asian population was first described in Korean children and adolescents with ADHD diagnosis. ${ }^{25}$ It was found

Table 4. The effects of genetic polymorphism (-1291C/G) and clinical demographics on the efficacy of MPH

\begin{tabular}{lccc}
\hline \multicolumn{1}{c}{ Independent variables } & OR & $95 \%$ CI & p-value \\
\hline Gender & 0.25 & $0.01-6.41$ & 0.40 \\
Age & 0.89 & $0.55-1.42$ & 0.62 \\
BMI & 0.90 & $0.75-1.09$ & 0.31 \\
Daily dose (mg/day) & 0.95 & $0.88-1.03$ & 0.24 \\
Genotype & & & \\
$\quad$ C/G vs. C/C & 5.98 & $0.43-82.45$ & 0.18 \\
G/G vs. C/C & 32.14 & $1.64-627.80$ & 0.02 \\
\hline
\end{tabular}

The MPH responsive subjects were categorized as moderate responders and better responders and subjected to binary logistic regression analysis. Those with and greater than $50 \%$ reduction in the SNAP-IV total scores were referred as better responders. OR: odds ratio, CI: confidence interval, MPH: methylphenidate, BMI: body mass index, SNAP-IV: Swanson, Nolan and Pelham version IV

Table 3. The clinical demographics of MPH moderate responders and better responders

\begin{tabular}{lccc}
\multicolumn{1}{c}{ Variables } & Moderate responder & Better responder & p-value \\
\hline Gender, female/male $(\mathrm{N})^{\mathrm{a}}$ & $1 / 17$ & $3 / 23$ & 0.49 \\
Age, years (mean $\pm \mathrm{SD})^{\mathrm{b}}$ & $11.44 \pm 1.68$ & $11.38 \pm 1.83$ & 0.91 \\
BMI (mean & $19.97 \pm 3.88$ & $18.19 \pm 3.59$ & 0.12 \\
Daily dose $\left(\mathrm{mg} /\right.$ day) $(\text { mean } \pm \mathrm{SD})^{\mathrm{b}}$ & $37.94 \pm 13.31$ & $34.00 \pm 9.90$ & 0.26 \\
\hline
\end{tabular}

The differences in the gender distribution, age, BMI and MPH daily dose between MPH moderate responders and better responders were examined by independent t-test (b) or chi-square test (a). MPH: methylphenidate, BMI: body mass index, SD: standard deviation 
that the homozygosity for the $\mathrm{G}$ allele was significantly associated with a better response ( $\geq 50 \%$ improvement) to $\mathrm{MPH}$ treatment. A more recent study with Korean children and adolescent on the other hand failed to demonstrate a significant association between the ADRA2A gene -1291C/G SNP and the effect of MPH for the treatment of ADHD. ${ }^{28}$ The results of our study with Taiwanese ADHD children and adolescents may provide explanation for the difference between their findings.

With the definition of more than $25 \%$ reduction in the SNAPIV total scores, $74.6 \%$ (44/59) of our subjects were shown to have a response to MPH treatment. This data is in accordance with the reports by other investigators $(65-80 \%))^{2,19,20}$ The response to MPH treatment in our subjects was not shown to be associated with the ADRA2A gene -1291C/G SNP by binary logistic regression analysis (Table 2). Further analysis on the responsive subjects revealed that the responders carrying $-1291 \mathrm{G}$ allele were inclined to have greater score reduction following MPH treatment (Figure 1). Statistical analysis, however, failed to demonstrate a significant difference among the genotypes. It might be because of a small sample size enrolled to study $(\mathrm{n}=44)$. A small sample size may result in a lack of sufficient power to detect any significant effect of the independent variable even if it exists in reality. We next performed the statistical analysis with the binary logistic regression model. In statistics, logistic regression is a regression model where the dependent variable is categorical. The binary logistic regression model is used to estimate the probability of a binary response based on one or more independent variables, and it has been widely used in medical fields. As the responsive subjects were categorized as moderate responders and better responders ( $\geq 50 \%$ improvement), the GG homozygotes were shown to have a higher rate of better responders (83.3\%). Furthermore, the chance for the GG homozygotes to become better responders was 32 times of the chance for $\mathrm{CC}$ homozygotes, in terms of odds ratio (Table 4). The CG heterozygotes also presented a greater chance to have a better response to $\mathrm{MPH}$ treatment than CC homozygotes. The odds ratio is 5.98 , but the difference did not reach statistical significance $(\mathrm{p}=0.18)$. From these results, it appears likely that the ADRA2A gene -1291C/ G SNP is associated with the efficacy of MPH for the treatment of ADHD in Taiwanese children and adolescents, and based on the fact that MPH exerts therapeutic effects through increasing the levels of DA and NE in PFC, ${ }^{9,15}$ it was suggested that the effect of NE on the prefrontal cortical pyramidal neurons to enhance the PFC function is associated with the ADRA2A gene $-1291 \mathrm{C} / \mathrm{G}$ SNP. The $-1291 \mathrm{G}$ allele might confer a better response to the ADRA2A receptor agonist, such as the neurotransmitter NE.

Since the -1291GG homozygotes exhibited a better response to MPH treatment, the data regarding the frequency of $-1291 \mathrm{G}$ allele in the ADRA2A gene may help estimate the frequency of the subjects who would exhibit a better response under MPH therapy. Previous studies found a lower frequency of -1291G allele $(0.26-0.38)$ in non-Asian children and adolescents with ADHD. ${ }^{27,29,39}$ Our study on the other hand revealed a higher frequency of - $1291 \mathrm{G}$ allele (0.63) in Taiwanese subjects. A high frequency of -1291G allele (0.67) was also reported in Korean children and adolescents with ADHD. ${ }^{25,28}$ From these data, we were speculating that $\mathrm{MPH}$ is more efficacious for the treatment of ADHD in Asian children and adolescents. Further studies with larger sample size including Asian and non-Asian subjects may help clarify this notion. This issue could be of interest from the drug company's point of view and the data would give us an insight into the etiology of ADHD.

Psychostimulants exert substantial effect on ADHD treatment are the current mainstay of ADHD therapy. ${ }^{1}$ But these drugs have the potential for abuse and may lead to severe psychological or physical dependence, raising concerns in clinical practice. Non-stimulants are recently emerged as a new option for the treatment of ADHD in children and adolescents, among which guanfacine received much attention. ${ }^{3}$ Guanfacine is a selective ADRA2A receptor agonist exerting therapeutic effects through stimulation of postsynaptic ADRA2A receptor on the dendritic spines of prefrontal cortical pyramidal neurons. Stimulation of the postsynaptic ADRA2A receptor inhibits the production of cyclic AMP and indirectly closes hyperpolarization-activated and cyclic nucleotide-gated ( $\mathrm{HCN})$ channels, thus increasing the functional connectivity of the prefrontal cortical networks. ${ }^{7}$ Stimulation of the ADRA2A receptor also promotes growth and maturation of the dendritic spines of pyramidal neurons of the medial PFC, that are associated with brain function such as learning and memory. ${ }^{7}$ As the ADRA2A gene -1291C/G SNP correlates with the efficacy of MPH in treating children and adolescents with ADHD (Cheon et al. ${ }^{25}$ and this study), the efficacy of guanfacine for the treatment of ADHD might be associated with the ADRA2A gene $-1291 \mathrm{C} / \mathrm{G}$ SNP. The data regarding this issue remain lacking and further studies are warranted.

This study has several limitations. First, we used only Chinese version of the Swanson, Nolan and Pelham version IV (SNAP-IV) Parent Form to assess the effect of MPH on ADHD-related symptoms in the participants. Secondly, our investigation assessed the short-term (4 weeks) effect of MPH treatment, was unable to provide the long-term outcome data. A long-term use of MPH has been defined as the patients received MPH treatment for more than 7 weeks, according to the package insert of Concerta ${ }^{\circledR}$ (Full prescribing information; 2.5 Maintenance/Extended Treatment, Janssen Pharmaceuticals Inc. 2008). Thirdly, despite the majority of our positive findings remained significant, our sample size is 
small. Finally, we cannot exclude the possibility that other polymorphisms in linkage disequilibrium with the ADRA2A gene $-1291 \mathrm{C} / \mathrm{G}$ variants may be responsible for the observed effects. Even with these limitations, our findings support a significant role of ADRA2A gene polymorphisms in the clinical response to $\mathrm{MPH}$ treatment in $\mathrm{ADHD}$, at least among Taiwanese children and adolescents.

Personalized medicine can be simply described as the prescription of specific therapeutics best suited for an individual. It could rely on the pharmacogenetics information. ${ }^{18,40}$ To our knowledge, this study is the first to correlate the ADRA2A gene $-1291 \mathrm{C} / \mathrm{G}$ SNP to the efficacy of MPH in treating Taiwanese children and adolescents with ADHD. Our results may help stratification of clinical response to MPH treatment and advance development of personalized medicine for ADHD treatment. But due to the small group of patients enrolled to study, more data are required before putting this idea into clinical practice.

\section{Supplementary Materials}

The online-only Data Supplement is available with this article at https://doi.org/10.30773/pi.2017.07.24.

\section{Acknowledgements}

We would like to thank Dr. Chun-Hui Wang for her help with subject recruitment, and medical technologist Li-Hua He for her assistance in blood specimen collection. This work was supported by research grants (No: 100023) from the Ministry of Health and Welfare, Taiwan.

\section{REFERENCES}

1. Chan E, Fogler JM, Hammerness PG. Treatment of attention-deficit/ hyperactivity disorder in adolescents: a systematic review. JAMA 2016; 315:1997-2008.

2. Rappley MD. Clinical practice. Attention deficit-hyperactivity disorder. N Engl J Med 2005;352:165-173.

3. Arnsten AF. The use of $\alpha-2 \mathrm{~A}$ adrenergic agonists for the treatment of attention-deficit/hyperactivity disorder. Expert Rev Neurother 2010;10: 1595-1605.

4. Arnsten AF, Dudley AG. Methylphenidate improves prefrontal cortical cognitive function through alpha2 adrenoceptor and dopamine D1 receptor actions: relevance to therapeutic effects in attention deficit hyperactivity disorder. Behav Brain Funct 2005;1:2.

5. Arnsten AF, Li BM. Neurobiology of executive functions: catecholamine influences on prefrontal cortical functions. Biol Psychiatry 2005;57: 1377-1384.

6. Cinnamon Bidwell L, Dew RE, Kollins SH. Alpha-2 adrenergic receptors and attention-deficit/hyperactivity disorder. Curr Psychiatry Rep 2010;12:366-373.

7. Alamo C, Lopez-Munoz F, Sanchez-Garcia J. Mechanism of action of guanfacine: a postsynaptic differential approach to the treatment of attention deficit hyperactivity disorder (ADHD). Actas Esp Psiquiatr 2016;44:107-112.

8. Gamo NJ, Wang M, Arnsten AF. Methylphenidate and atomoxetine enhance prefrontal function through alpha2-adrenergic and dopamine D1 receptors. J Am Acad Child Adolesc Psychiatry 2010;49:1011-1023.

9. Stahl SM. Mechanism of action of alpha $2 \mathrm{~A}$-adrenergic agonists in attention-deficit/hyperactivity disorder with or without oppositional symptoms. J Clin Psychiatry 2010;71:223-224.
10. Hanwella R, Senanayake M, de Silva V. Comparative efficacy and acceptability of methylphenidate and atomoxetine in treatment of attention deficit hyperactivity disorder in children and adolescents: a metaanalysis. BMC Psychiatry 2011;11:176.

11. Heal DJ, Cheetham SC, Smith SL. The neuropharmacology of ADHD drugs in vivo: insights on efficacy and safety. Neuropharmacology 2009;57:608-618.

12. Wigal SB. Efficacy and safety limitations of attention deficit hyperactivity disorder Pharmacotherapy in pediatric patients. J Pediatr 2009; 154:S13-S21.

13. Arnsten AF. The emerging neurobiology of attention deficit hyperactivity disorder: the key role of the prefrontal association cortex. J Pediatr 2009;154:S22-S31.

14. Volkow ND, Wang G, Fowler JS, Logan J, Gerasimov M, Maynard L, et al. Therapeutic doses of oral methylphenidate significantly increase extracellular dopamine in the human brain. J Neurosci 2001;21:RC121.

15. Del Campo N, Chamberlain SR, Sahakian BJ, Robbins TW. The roles of dopamine and noradrenaline in the pathophysiology and treatment of attention-deficit/hyperactivity disorder. Biol Psychiatry 2011;69: e145-e157.

16. Bonvicini C, Faraone SV, Scassellati C. Attention-deficit hyperactivity disorder in adults: a systematic review and meta-analysis of genetic, pharmacogenetic and biochemical studies. Mol Psychiatry 2016;21: 872-884.

17. Froehlich TE, McGough JJ, Stein MA. Progress and promise of attention-deficit hyperactivity disorder pharmacogenetics. CNS Drugs 2010; 24:99-117.

18. Zaiou M, El Amri H. Cardiovascular pharmacogenetics: a promise for genomically-guided therapy and personalized medicine. Clin Genet 2017;91:355-370.

19. Steele M, Jensen PS, Quinn DM. Remission versus response as the goal of therapy in ADHD: a new standard for the field? Clin Ther 2006;28: 1892-1908.

20. Vaughan B, Kratochvil CJ. Pharmacotherapy of pediatric attentiondeficit/hyperactivity disorder. Child Adolesc Psychiatr Clin N Am 2012; 21:941-955.

21. Purper-Ouakil D, Ramoz N, Lepagnol-Bestel AM, Gorwood P, Simonneau M. Neurobiology of attention deficit/hyperactivity disorder. Pediatr Res 2011;69:69R-76R.

22. Levy F. Applications of pharmacogenetics in children with attentiondeficit/hyperactivity disorder. Pharmgenomics Pers Med 2014;7:349-356.

23. Comings DE, Gade-Andavolu R, Gonzalez N, Blake H, Wu S, MacMurray JP. Additive effect of three noradrenergic genes (ADRA2a, ADRA2C, $\mathrm{DBH}$ ) on attention-deficit hyperactivity disorder and learning disabilities in Tourette syndrome subjects. Clin Genet 1999;55:160-172.

24. Roman T, Polanczyk GV, Zeni C, Genro JP, Rohde LA, Hutz MH. Further evidence of the involvement of alpha-2A-adrenergic receptor gene (ADRA2A) in inattentive dimensional scores of attention-deficit/hyperactivity disorder. Mol Psychiatry 2006;11:8-10.

25. Cheon KA, Cho DY, Koo MS, Song DH, Namkoong K. Association between homozygosity of a $\mathrm{G}$ allele of the alpha-2a-adrenergic receptor gene and methylphenidate response in Korean children and adolescents with attention-deficit/hyperactivity disorder. Biol Psychiatry 2009; 65:564-570.

26. da Silva TL, Pianca TG, Roman T, Hutz MH, Faraone SV, Schmitz M, et al. Adrenergic alpha2A receptor gene and response to methylphenidate in attention-deficit/hyperactivity disorder-predominantly inattentive type. J Neural Transm (Vienna) 2008;115:341-345.

27. Polanczyk G, Zeni C, Genro JP, Guimaraes AP, Roman T, Hutz MH, et al. Association of the adrenergic alpha2A receptor gene with methylphenidate improvement of inattentive symptoms in children and adolescents with attention-deficit/hyperactivity disorder. Arch Gen Psychiatry 2007;64:218-224.

28. Park S, Kim JW, Kim BN, Hong SB, Shin MS, Yoo HJ, et al. No significant association between the alpha-2A-adrenergic receptor gene and 
treatment response in combined or inattentive subtypes of attentiondeficit hyperactivity disorder. Pharmacopsychiatry 2013;46:169-174.

29. Unal D, Unal MF, Alikasifoglu M, Cetinkaya A. Genetic variations in attention deficit hyperactivity disorder subtypes and treatment resistant cases. Psychiatry Investig 2016;13:427-433.

30. Redinbo MR, Bencharit S, Potter PM. Human carboxylesterase 1: from drug metabolism to drug discovery. Biochem Soc Trans 2003;31:620624 .

31. Sun Z, Murry DJ, Sanghani SP, Davis WI, Kedishvili NY, Zou Q, et al. Methylphenidate is stereoselectively hydrolyzed by human carboxylesterase CES1A1. J Pharmacol Exp Ther 2004;310:469-476.

32. Nemoda Z, Angyal N, Tarnok Z, Gadoros J, Sasvari-Szekely M. Carboxylesterase 1 gene polymorphism and methylphenidate response in ADHD. Neuropharmacology 2009;57:731-733.

33. Zhu HJ, Patrick KS, Yuan HJ, Wang JS, Donovan JL, DeVane CL, et al. Two CES1 gene mutations lead to dysfunctional carboxylesterase 1 activity in man: clinical significance and molecular basis. Am J Hum Genet 2008;82:1241-1248.

34. Gau SS, Lin CH, Hu FC, Shang CY, Swanson JM, Liu YC, et al. Psychometric properties of the Chinese version of the Swanson, Nolan, and Pelham, Version IV Scale-Teacher Form. J Pediatr Psychol 2009;34:850-
861

35. Gau SS, Shang CY, Liu SK, Lin CH, Swanson JM, Liu YC, et al. Psychometric properties of the Chinese version of the Swanson, Nolan, and Pelham, version IV scale-parent form. Int J Methods Psychiatr Res 2008; 17:35-44.

36. Liu YC, Liu SK, Shang CT, Lin CH, Tu C, Gau SF. Norm of the Chinese Version of the Swanson, Nolan and Pelham, Version IV Scale for ADHD. Taiwan J Psychiatry 2006;20:290-304.

37. Su Y, Yang L, Stein MA, Cao Q, Wang Y. Osmotic release oral system methylphenidate versus atomoxetine for the treatment of attentiondeficit/hyperactivity disorder in chinese youth: 8-week comparative efficacy and 1-year follow-up. J Child Adolesc Psychopharmacol 2016; 26:362-371.

38. Lario S, Calls J, Cases A, Oriola J, Torras A, Rivera F. MspI identifies a biallelic polymorphism in the promoter region of the alpha 2A-adrenergic receptor gene. Clin Genet 1997;51:129-130.

39. Schmitz M, Denardin D, Silva TL, Pianca T, Roman T, Hutz MH, et al. Association Between Alpha-2a-adrenergic Receptor Gene and ADHD Inattentive Type. Biol Psychiatry 2006;60:1028-1033.

40. Webster LR, Belfer I. Pharmacogenetics and personalized medicine in pain management. Clin Lab Med 2016;36:493-506. 